\title{
Post Traumatic Hematocele - Ultrasonography and Elastography Imaging
}

\author{
Shivesh Pandey ${ }^{1}$, Suresh Vasant Phatak ${ }^{2}$, Gopidi Sai Nidhi Reddy ${ }^{3}$, Apoorvi Bharat Shah ${ }^{4}$ \\ 1, 2, 3,4 Department of Radio diagnosis, Jawaharlal Nehru Medical College, \\ Sawangi (Meghe), Wardha, Maharashtra India.
}

\section{INTRODUCTION}

Hematocele with blunt scrotal trauma is an uncommon cause of the testicular pain. Elastography is the new recent advance in the field of ultrasound. USG and elastography findings of the acute hematocele is described in this aricle.

Testicular trauma is the third most common cause of acute scrotal pain, ${ }^{1}$ and high-frequency ultrasonography (USG) with a linear array transducer is the first preferred modality for testicular trauma evaluation. Extra testicular haematoceles or blood collections inside the tunica vaginalis are the most common findings in the scrotum after blunt injury. ${ }^{2}$ On clinical assessment, haematocele appears as a hard mass like swelling and causes pain in the scrotum. In the majority of cases, spontaneous resolution occurs with the support of conservative therapy, ${ }^{3}$ even if treated conservatively, may result in infection, discomfort, or atrophy in undiagnosed broad hematoceles and testicular hematomas over time. ${ }^{4}$

A testis with its coverings, epididymis, and spermatic cord are all contained in each hemiscrotum. A typical testis is $5 \times 3 \times 2 \mathrm{~cm}$ in diameter and has an intermediate echogenicity. The tunica albuginea is a fibrous covering that protects the testis from damage from the external injuries. It is located on top of the tunica vasculosa, which is made up of capsular arteries. A testis with its coverings, epididymis, and spermatic cord are all contained in each hemiscrotum. With its high tensile strength, the tunica albuginea plays an important role in shielding the testis from trauma. It can withstand a force of up to $50 \mathrm{~kg}$ without bursting. The testicular parenchyma is made up of several lobules, each of which is made up of several seminiferous tubules that lead to dilated spaces inside the mediastinum called the rete testis through the tubuli recti. The epididymis is made up of a head, neck, and tail that protects the superolateral part of the testis. The epididymis' tail ends in the spermatic cord as the vas deferens. The epididymal head is a $5-12 \mathrm{~mm}$ pyramidal structure that sits atop the testis' superior pole. The head is almost isoechoic to the testis. The epididymis has a $2-4$ mm thick body. ${ }^{5}$

The patient lies in a supine position with the scrotum covered by a towel positioned between the thighs during scrotal ultrasound. A high-frequency lineararray transducer with a frequency range of $7-14 \mathrm{MHz}$ is preferred. The scrotum is always soft to the touch after trauma, making scanning difficult. It should be attempted to examine both the testes and the epididymis in their entirety, as well as any extra testicular lesions. The testes are assessed in two planes: longitudinal and transverse. Each testis and epididymis should be compared to the contralateral testis and epididymis in terms of size and echogenicity. Transverse scrotal imaging is important for depicting both testes and comparing their gray-scale and colour Doppler appearances.
Corresponding Author: Dr. Suresh Vasant Phatak, Department of Radiodiagnosis, Jawaharlal Nehru Medical College, Sawangi (Meghe), Wardha, Maharashtra - 442001, India. E-mail: suresh_phatak@yahoo.com

DOI: $10.14260 / j e m d s / 2021 / 340$

How to Cite This Article:

Pandey S, Phatak SV, Reddy GSN, et al. Post traumatic hematocele - usg and elastography imaging. J Evolution Med Dent Sci 2021;10(21):1636-1638, DOI: $10.14260 / j e m d s / 2021 / 340$

Submission 05-01-2021,

Peer Review 24-03-2021,

Acceptance 30-03-2021,

Published 24-05-2021.

Copyright (C) 2021 Shivesh Pandey et al. This is an open access article distributed under Creative Commons Attribution License [Attribution 4.0 International (CC BY 4.0)] 
Blood flow in the testis and surrounding scrotal structures should be recorded by obtaining Doppler spectra of the intra testicular arterial flow in both testes, and colour Doppler and pulsed Doppler US should be designed to represent low flow velocities. Ideally each testicle should have three spectral Doppler recordings (preferably, in upper, middle, and lower thirds). In patients with acute scrotal pain, a Power Doppler can also be used to see the intra testicular blood flow. 4

The testes are protected by their mobility within the scrotum, the laxity of the overlying tissue, the cremasteric muscles' contraction reflex, and the tunica albuginea. While genital skin laxity can protect underlying organs from blunt trauma by allowing them to slip away from the point of contact, excessive skin laxity may result in severe injuries if the genital skin becomes entrapped in spinning machinery, resulting in avulsion and rupture of either or both testes.6,7 Sports-related testicular injuries account for more than half of all testicular injuries, while motor vehicle collisions account for another $9 \%-17 \%$ of testicular injuries. ${ }^{8}$ Blunt injuries, penetrating injuries, and iatrogenic injuries are the three major forms of scrotal injuries.

The high energy transmitted during interaction with a solid object causes blunt injuries, which are non-invasive (e.g., from a kick to the groin or the impact of a baseball or hockey stick). Crushing of the testis against the symphysis pubis or between the thighs is the primary mechanism of injury in blunt trauma.

The right testis is more likely to be damaged in this way than the left testis, ${ }^{9}$ possibly because it is anatomically slightly higher than the left testis in most males. Sharp object and projectile wounds (e.g., scissors, bullets), as well as animal bites and self-mutilation injuries, are all examples of penetrating injuries. Complications of inguinal herniorrhaphy or orchiectomy often result in iatrogenic injuries to the scrotal contents.

Nerve damage and infection are the two most common complications of inguinal and scrotal surgery. ${ }^{10,11}$ Spermatic cord transection is another common complication, which may result in bleeding from the spermatic cord veins, large scrotal hematomas, and progressive scrotal swelling. About $30 \%$ of penetrating injuries are more likely to be bilateral. ${ }^{12,13}$

\section{PRESENTATION OF CASE}

A 65-year-old gentleman presented with a firm, tender right sided scrotal swelling and was referred for ultrasound. Patient had history of trauma by bicycle rod one week ago. USG was done with a linear transducer $12-18 \mathrm{MHz}$ which showed a well-defined hyper echoic lesion of size $52 \times 40 \mathrm{~mm}$ showing internal debris and fluid debris level (Figure 1).

This lesion was anterosuperior to the testis in right testis, which was compressed by this lesion and was normal in size, shape, echo structure and vascularity (Figure 2). Left testis was normal in shape, size and vascularity.

Epididymis was normal bilaterally. On strain elastography this lesion revealed classical BGR (Blue Green Red) appearance. (Figure 3)
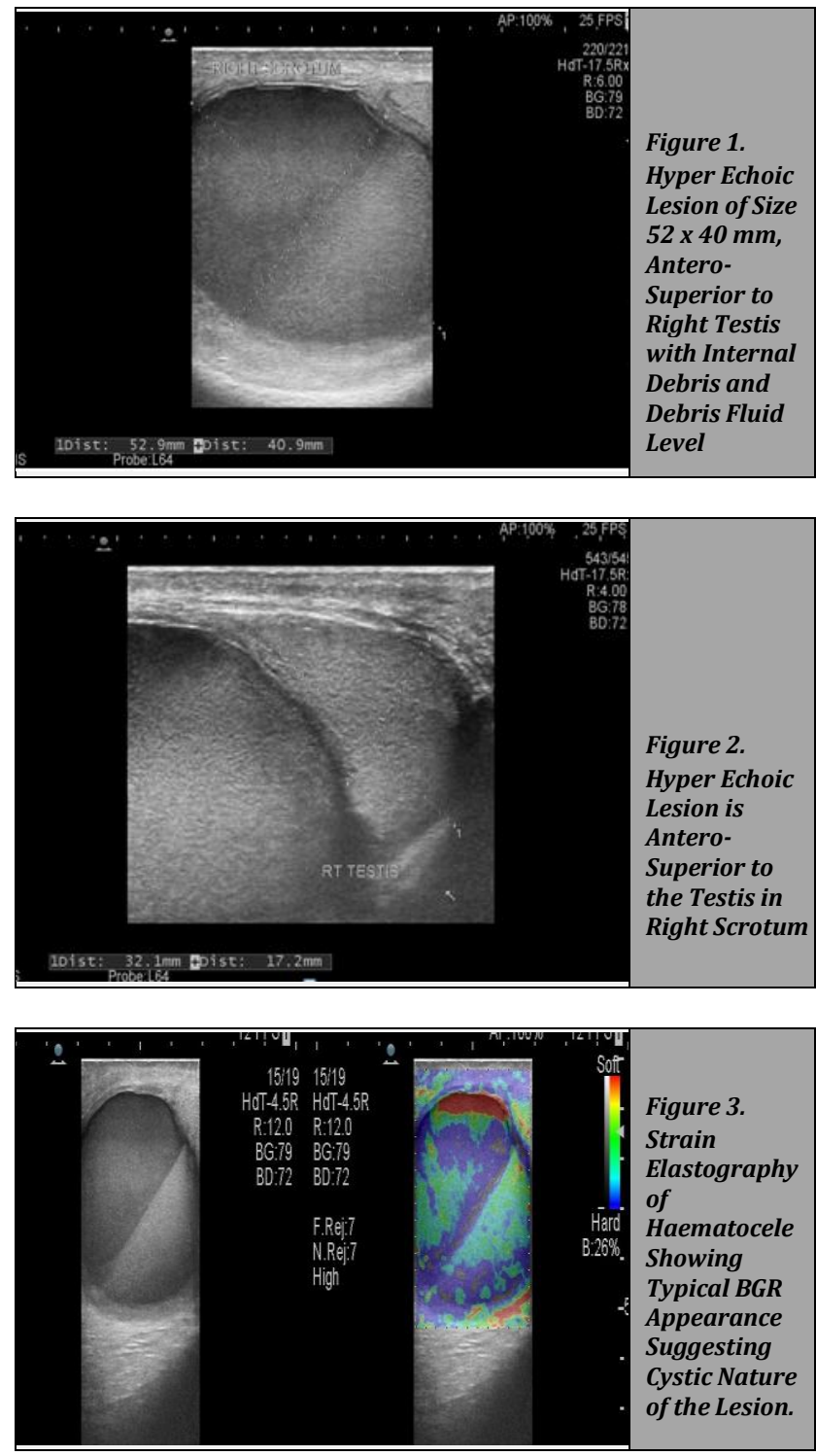

\section{DISCUSSION}

Testicular rupture or laceration due to direct scrotal trauma is the most common cause of scrotal hematoceles. In the few cases where scrotal hematoceles are not associated with a history of scrotal trauma, intraperitoneal or retroperitoneal bleeding should be suspected.

Depending on the time after the trauma, haematocele will manifest in a number of ways in USG. Acute haematocele has a hyper echoic appearance at first, then a cystic appearance after 14 - 15 days, ${ }^{14}$ with complex septations, fluid-fluid level, and subtle echoes.

The acute onset of a major haematocele can result in decreased blood flow to the testes due to extrinsic pressure on the arteries, and thus may resemble testicular torsion or partial torsion. 4

The presence of hematocele in the Ultrasound varies depending on the time of evaluation. It appears as an echoic fluid collection in the acute process, then becomes hypoanechoic over time. Internal echoes generated by haemoglobin breakdown products can also be noticeable on the picture. ${ }^{15}$ 
The 3 - layer pattern (blue / green / red layers) seen in smaller cystic areas is referred to as the BGR symbol in elastography. This pattern is useful because it illustrates the cystic nature of the lesion and has been observed in cystic lesions with internal echogenic material. 16

The MRI results are consistent with met haemoglobin degradation in other tissues. In chronic hematomas, T2weighted images may have a variable appearance, and a hypo signal halo due to hemosiderin deposition may occur. ${ }^{14}$ In cases of testicular damage, magnetic resonance imaging is also useful in detecting tunica albuginea rupture, which necessitates surgical intervention. ${ }^{17}$

\section{CONCLUSIONS}

In the case of acute scrotal trauma, sonography is the first line of treatment. With the advent of recent advances such as elastography, the sensitivity and accuracy of early diagnosis has improved even further, allowing for better patient management.

Financial or other competing interests: None.

Disclosure forms provided by the authors are available with the full text of this article at jemds.com.

\section{REFERENCES}

[1] Ragheb D, Higgins Jr JL. Ultrasonography of the scrotum: technique, anatomy and pathologic entities. J Ultrasound Med 2002;21(2):171-85.

[2] Micallef M, Ahmad I, Ramesh N, et al. Ultrasound features of blunt testicular injury. Injury 2001;32(1):23-6.

[3] Woodward PJ, Schwab CM, Sesterhenn IA. From the archives of the AFIP: extratesticular scrotal masses: radiologic-pathologic correlation. Radiographics 2003;23(1):215-40.

[4] Bhatt S, Dogra VS. Role of US in testicular and scrotal trauma. Radiographics 2008;28(6):1617-29.

[5] Dogra VS, Gottlieb RH, Oka M, et al. Sonography of the scrotum. Radiology 2003;227(1):18-36.

[6] Wessells H, Long L. Penile and genital injuries. Urol Clin North Am 2006;33(1):117-26, vii.

[7] Adigun IA, Kuranga SA, Abdulrahman LO. Grinding machine: friend or foe. West Afr J Med 2002;21(4):33840.

[8] Haas CA, Brown SL, Spirnak JP. Penile fracture and testicular rupture. World J Urol 1999;17(2):101-6.

[9] Mulhall JP, Gabram SG, Jacobs LM. Emergency management of blunt testicular trauma. Acad Emerg Med 1995;2(7):639-43.

[10] Ridgway PF, Shah J, Darzi AW. Male genital tract injuries after contemporary inguinal hernia repair. BJU Int 2002;90(3):272-6.

[11] Taylor EW, Duffy K, Lee K, et al. Surgical site infection after groin hernia repair. Br J Surg 2004;91(1):105-11.

[12] Cass AS, Ferrara L, Wolpert J, et al. Bilateral testicular injury from external trauma. J Urol 1988;140(6):1435-6.

[13] Cass AS, Luxenberg M. Testicular injuries. Urology 1991;37(6):528-30.

[14] Kim W, Rosen MA, Langer JE, et al. US-MR imaging correlation in pathologic conditions of the scrotum. Radiographics 2007;27(5):1239-53.

[15] Deurdulian C, Mittelstaedt CA, Chong WK, et al. US of acute scrotal trauma: optimal technique, imaging findings and management. Radiographics 2007;27(2):357-69.

[16] Cho N, Moon WK, Chang JM, et al. Aliasing artifact depicted on ultrasound (US)-elastography for breast cystic lesions mimicking solid masses. Acta Radiol 2011;52(1):3-7.

[17] Parenti GC, Feletti F, Brandini FR, et al. Imaging of the scrotum: role of MRI. La Radiol Med 2009;114(3):414-24. 